\title{
WALKING WOUNDED OR LIVING DEAD? MAKING BANKS FORECLOSE BAD LOANS
}

\author{
Max Bruche and Gerard Llobet
}

CEMFI Working Paper No. 1003

June 2010

CEMFI

Casado del Alisal 5; 28014 Madrid

Tel. (34) 914290551 Fax (34) 914291056

Internet: www.cemfi.es

We would like to express our thanks for all the helpful comments and suggestions received on prior drafts of this paper, including those from seminar participants at CEMFI, Princeton, and the New York Fed. 
CEMFI Working Paper 1003

June 2010

\title{
WALKING WOUNDED OR LIVING DEAD? MAKING BANKS FORECLOSE BAD LOANS
}

\begin{abstract}
Due to limited liability, banks that are essentially insolvent may have incentives to roll over bad loans as a gamble for resurrection, even though it is socially inefficient to do so. This paper considers the problem of making such banks remove and/or foreclose bad loans, when the proportion of loans on a bank's balance sheet that has gone bad is private information. The private information implies that many plausible schemes are likely to generate windfall gains for bank equity holders, which is undesirable. We propose a scheme with voluntary participation, under which banks (i) reveal the proportion of bad loans on their balance sheet, (ii) remove or foreclose them, and (iii) bank equity holders are no better off than they would be in the absence of the scheme, that is, the scheme produces no windfall gains for bank equity holders.
\end{abstract}

Max Bruche

CEMFI

bruche@cemfi.es
Gerard Llobet

CEMFI

llobet@cemfi.es 


\section{Introduction}

During the recent financial crisis, there was a concern that some banks might become "zombies", that is, that they would continue to operate even though insolvent. One of the main risks with such zombie banks is that they can have incentives to roll over loans of firms that are also insolvent instead of foreclosing — in an attempt to gamble for resurrection. This behaviour, sometimes referred to as zombie lending, evergreening, or forbearance lending, can have very bad effects for the economy as a whole. This behavior has been documented, for example, for Japan during the 90s by Peek and Rosengren (2005). ${ }^{1}$

Asset buybacks are a common example of the type of measures that policymakers consider in order to restore bank solvency and hence to prevent zombie lending. ${ }^{2}$ These buybacks consist of transactions in which a regulator sets up a special purpose vehicle which then buys bad assets off bank's balance sheets, typically at inflated prices so as to implicitly recapitalize banks. During the recent crisis, in the US, an asset buyback was proposed by the (then) US Treasury Secretary Paulson. This proposal was heavily criticized because it was thought that under the scheme, bank equity holders would have obtained windfall gains. ${ }^{3}$ In the end, the scheme was not implemented. In Ireland, a buyback scheme has been approved, but has also been heavily criticized for similar reasons. ${ }^{4}$

The general problem with such schemes is that it is often hard to know whether a given bank is part of the "walking wounded" (the bank has taken a hit but is still fundamentally solvent) or the "living dead" (the bank has taken a hit and is now essentially insolvent). If the extent of solvency problems is private information of a bank, this can limit the ability of the regulator to prevent bank equity holders from obtaining windfall gains from a scheme. Such windfall gains are problematic because they are perceived as a reward to banks that have taken unnecessary risks, because they may distort ex-ante incentives, and because they are socially costly due to the taxation necessary to finance them, resulting in a lack of popular

\footnotetext{
${ }^{1}$ Caballero, Hoshi, and Kayshap (2008) discuss how such forbearance lending can negatively effect the whole economy via crowding out effects, and illustrate these with Japanese data.

${ }^{2}$ Other standard responses of governments and central banks to a banking crisis include measures such as a lowering of policy rates, loan guarantees to banks, lending to banks against bad collateral, and various forms of bank recapitalizations. See, for example, Caprio and Klingebiel (1996) for a description of bank crises up until the mid 90s.

${ }^{3}$ See Hoshi and Kayshap (2009) for a description of the measures taken in the US during the current crisis and a comparison to the measures taken in Japan during the Japanese crisis.

${ }^{4}$ For information on the Irish buyback vehicle, called NAMA, see "Nama to pay 54bn EUR for bank loans of 77bn EUR in rescue plan," Irish Times, Sep 17, 2009. Prominent critics include Joseph Stiglitz, who stated that the transfer of wealth from the general population to the financial sector as implicit in the Irish scheme was something that frequently happened in "banana republics", see "Nama is highway robbery", Sunday Business Post, Oct 11, 2009.
} 
support.

The question that we address in this paper is to what extent the careful design of interventions can get around this problem. We consider a situation in which banks have private information on the quantity of loans that have gone bad on their balance sheet. The contribution of this paper is to propose a scheme with voluntary participation under which (i) banks reveal this private information, (ii) remove and/or foreclose all their bad loans, and (iii) bank equity holders are no better off than they would be in the absence of the scheme. That is, the scheme affords no windfall gains to bank equity holders. ${ }^{5}$

In our model, banks have good and bad loans on their balance sheet, and the proportion of bad loans is private information. Good loans always produce a higher return than bad loans. Banks decide how many bad loans to foreclose. Foreclosing a bad loan means realizing an immediate loss on the loan. Rolling over a bad loan means delaying the resolution of uncertainty about the loss on the loan. We assume that in expected net present value terms, foreclosing produces a smaller loss than rolling over. ${ }^{6}$ In the absence of a scheme, banks that have few bad loans foreclose all of their bad loans, and banks that have many bad loans foreclose none of their bad loans, engaging in forbearance lending as a gamble for resurrection. This happens because of convexities introduced by limited liability of banks and is a standard limited liability distortion.

In the simplest implementation of our scheme, the regulator offers a menu of two-part tariffs to the banks. In each tariff, a bank pays an initial flat fee to participate, and then receives a subsidy per unit of loans that it forecloses. Alternatively, our scheme can be interpreted as an asset buyback scheme, in which a bank pays an initial flat fee to participate, and then receives an associated price for each loan that it sells to a special purpose vehicle, which then forecloses. The role of the subsidy (or the price in case of the asset buyback) is to induce foreclosure, and the role of the fee is to claw back (some or all of) the increase in equity value produced by the subsidy or price.

Naturally, contracts that offer a higher subsidy are associated with a higher flat fee. When faced with this menu, banks with a higher proportion of bad loans will select contracts with a higher subsidy and a higher flat fee. This is because they have more bad loans to sell, and therefore care more about obtaining a higher price for their loans.

\footnotetext{
${ }^{5}$ Although schemes with mandatory as opposed to voluntary participation (such as e.g. a full scale nationalizations of all banks) typically cost less and pose less of a problem in terms of mechanism design, they are often politically infeasible. We therefore believe that an examination of schemes with voluntary participation is of interest. See also Section 4 for a discussion.

${ }^{6}$ For example, this could be microfounded with a model in which insolvent borrowers whose loans are rolled over have incentives themselves to destroy value by gambling for resurrection.
} 
We show that under such a scheme, banks have incentives both to overstate their proportion of bad loans (to pretend that they are more reluctant to foreclose, and hence should be charged lower fees), and to understate their proportion of bad loans (to pretend that they benefit less from the subsidies, and hence should be charged lower fees). These countervailing incentives can be played off against each other to reduce information rents. In fact, the optimal contract exactly balances these incentives, and in doing so, completely eliminates information rents. We show that the properties of the model that make this exact balancing possible are the very same properties that lead to the gambling behaviour in the first place, namely, limited liability and the fact that rolling over bad loans delays the resolution of uncertainty.

In general, in order for banks to participate and give up their bad loans, the net transfers to them have to be positive (although equity holders do not benefit from the scheme, debt holders do). We show that the size of the required net transfer for a bank to participate is increasing and convex in the proportion of bad loans on its balance sheet whereas the welfare gain from having a bank participate is increasing and linear in the proportion of bad loans on its balance sheet. Consequently, and once we account for the social cost associated with raising funds, the optimal intervention targets only banks with intermediate proportions of bad loans.

We also discuss when our scheme is robust to a situation in which banks can foreclose good loans in order to obtain higher transfers from the regulator, how versions of the scheme could be implemented if the regulator knew less than we assumed, how deposit insurance, a social cost of bank failure, and potential bank runs would affect the welfare trade-off, and finally also briefly discuss schemes with mandatory as opposed to voluntary participation, especially in the context of ex-ante moral hazard.

Related literature Many papers, including those of Mitchell (1998), Aghion, Bolton, and Fries (1999), Corbett and Mitchell (2000), and Mitchell (2001) examine models in which the amount of bad debt on a bank's balance sheet is private information and bank managers can hide bad loans via rolling them over. Mitchell (1998) shows how the inability of a regulator to commit to not bailing out banks during large crises can lead to a situation in which very insolvent banks will reveal their situation, but marginally insolvent banks will hide their situation by rolling over. Aghion, Bolton, and Fries (1999) argue that there is a tradeoff between having "tough" closure policies for banks, which gives incentives to hide problems ex-post but provides incentives not to take risks ex-ante, and having "soft" closure policies for banks, which does not give incentives to hide problems ex-post, but provides incentives to 
take risks ex-ante. They also sketch a second-best scheme that involves transfers conditional on the liquidation of non-performing loans. ${ }^{7}$ Corbett and Mitchell (2000) show how bank managers that are concerned about their reputation might reject recapitalization offers to safeguard this reputation, which has the effect of prolonging banking crises. Mitchell (2001) emphasizes how rolling over bad loans creates incentive problems at firms, and compares a laissez-faire policy, transfers of bad loans to a "bad bank", and a cancellation of existing firm debt.

There are some papers that are motivated by the recent crisis and apply ideas from mechanism design to the problem of intervention. For example, Philippon and Schnabl (2009) consider a debt overhang problem, in a situation in which the quality of in-place assets as well as the quality of new investment opportunities is private information of the banks. Whereas Philippon and Schnabl (2009) emphasize heterogeneity in the quality of new investment opportunities, we emphasize heterogeneity in the quantity of the proportion of bad in-place assets (bad loans). Consequently, the optimal intervention in their case makes banks sell warrants - the willingness of a bank to part with warrants can reveal information about the quality of new investment opportunities, whereas our optimal invervention has banks sell bad loans - the willingness of banks to sell loans in an asset buyback can reveal information about the quantity of bad loans on the bank's balance sheet.

In a setting similar to that of Philippon and Schnabl (2009), Philippon and Skreta (2010) study the adverse selection problem that can arise in the interbank market for funds, when a government scheme provides an alternative source of funds. Participation or nonparticipation of a given group of banks in the scheme can affect the average "quality" of a borrower in the interbank market, and hence the outside opportunities of other banks. An optimal scheme needs to take into account this interaction. Although an interesting issue, we abstract from such problems here to focus on our core message.

There is also a literature that views asset buybacks as a solution to the problem of firesale discounts. For example, Diamond and Rajan (2009) argue that in a situation in which banks can be hit by liquidity shocks that force them to sell assets at a fire-sale discount, and current private buyers anticipate the potential future fire-sale discount, the regulator can ensure bank liquidity in the future by buying assets now, at prices above those that current private buyers are willing to pay, but below the fundamental value of the asset. In the same spirit, but in a general equilibrium setting, Gorton and Huang (2004) show that it can be more efficient for the government rather than the private sector to provide liquidity

\footnotetext{
${ }^{7}$ This scheme can be interpreted as a (partial) implementation of our optimal contract. See Subsection 3.3 .
} 
by buying up bank assets. In this context, some work has also been done on how to design auctions to ensure that the regulator does not overpay for the assets that it is buying. ${ }^{8}$

In contrast, in our model, asset buybacks are a solution to the problem of inefficient gambling for resurrection by banks. Since banks want to gamble, anyone attempting to buy a bad asset will necessarily have to pay more than fundamental value in order for a such a bank to want to part with the bad asset. As we show, overpaying for the bad asset does not necessarily imply windfall gains for bank equity holders.

Our paper is also related to the general mechanism design literature. The two-part tariff implementation of our optimal contract turns out to be mathematically similar to the original problem of Baron and Myerson (1982), except that we have a type-dependent outside option. This creates countervailing incentives as in Lewis and Sappington (1989). In our case, though, the type-dependent outside option is not concave but convex in types, due to the convexity introduced by limited liability, which means that information rents can be eliminated as in Maggi and Rodríguez-Clare (1995).

In the next Section 2 the basic model is set up. In section 3, we derive the optimal contract - Subsection 3.1 sets up the general optimal contracting problem, 3.2 considers the simpler problem of deriving the optimal two-part tariff, and 3.3 shows that the optimal two-part tariff is in fact an implementation of the solution to the more general problem. Section 4 considers some extensions, and Section 5 concludes. All proofs are in the appendix.

\section{The model}

Consider an economy with two dates $t=1,2$. There is no discounting across periods. There exists a continuum of risk-neutral banks. All banks have a balance sheet of size 1, and the same amount of debt $D$ and initial equity $1-D$, where $0<D<1$. The face value of debt, $D$, is due to be paid at $t=2$. The only assets on the banks' balance sheets are loans. Loans can either be good or bad. At date $t=1$, each bank learns what proportion $\theta$ of its loans are bad loans, and what proportion $1-\theta$ of its loans are good loans. The proportion $\theta$ varies across banks and is private information. The distribution of $\theta$ in the population of banks is denoted as $\Psi(\theta)$ with density $\psi(\theta)$.

At $t=1$, after learning $\theta$, banks can decide what amount $\gamma$ of bad loans they want to foreclose, where $\gamma \in[0, \theta]$. The remaining bad loans, a proportion $\theta-\gamma$, is rolled over. Any loan that is foreclosed at $t=1$ produces a recovery of $\rho$. We assume that the bank cannot

\footnotetext{
${ }^{8}$ See, for example, the schemes proposed by Ausubel and Cramton (2008) or Klemperer (2010)
} 
pay dividends at $t=1$ such that the proceeds from foreclosure are carried forward until $t=2$.

At $t=2$, any good loan pays off 1 . Bad loans that were not foreclosed but instead rolled over at $t=1$ are foreclosed now. Any such loan produces a recovery of $\varepsilon$, where $\varepsilon \in[0,1]$. At $t=1$, the bank does know what the value of $\varepsilon$ will be at $t=2$. Its belief over $\varepsilon$ is represented by the distribution $\Phi(\varepsilon)$, with corresponding density $\phi(\varepsilon) .{ }^{9}$ We assume that $\phi$ has full support on $[0,1]$. We assume that $E[\varepsilon]<\rho$, so that it is socially optimal for banks to immediately foreclose their bad loans, since this maximizes the net present value. ${ }^{10}$

In the next section, we will also introduce a risk-neutral regulator that will attempt to influence the foreclosure decisions of banks by offering a menu of contracts. To afford an informational advantage to the banks, we assume that the regulator does not know $\theta$. Furthermore, the regulator will neither observe the value of assets of a bank at $t=2$, nor the realization of $\varepsilon$. This means that the regulator will also not be able to indirectly infer the proportion of bad loans on a bank's balance sheet. We will assume, though, that the regulator observes the proportion of bad loans being foreclosed, $\gamma$, and can write contracts contingent on it. This allows, for example, contracts that pay a subsidy per foreclosed loan, or a buyback scheme in which the regulator sets up a special purpose vehicle that buys bad loans from a bank and then forecloses. Although this will turn out not to be crucial, we can also allow for contracts that condition on whether or not a bank survives.

Banks operate under limited liability. If in the second period the realized $\varepsilon$ is sufficiently low, a bank will not be able to repay its existing debt. A bank that chooses to foreclose an amount of bad loans $\gamma$ will survive if

$$
1-\theta+(\theta-\gamma) \varepsilon+\gamma \rho>D
$$

That is, a bank will survive if it can repay $D$ in full with the return of the good loans together with the return from bad loans that have been rolled over - which depends on the realized $\varepsilon$ - and the return from the foreclosed loans. In other words, the bank will be able to repay $D$ as long as the realized $\varepsilon$ is sufficiently high, or if

$$
\varepsilon \geq \bar{\varepsilon}_{0} \equiv \frac{\theta-\gamma \rho-(1-D)}{\theta-\gamma} .
$$

\footnotetext{
${ }^{9}$ As an illustration of the payoffs on bad loans, consider the following example: A bank has lent to many property developers, whose debt is due now at $t=1$, and finds out that some of them are unable to repay. The bank can seize the collateral (real estate) now and sell it at price $\rho$, or it can roll over the loans to foreclose later, and hope that the property market improves. The bank's belief over the future values of the collateral and hence the future recoveries is described by $\phi(\varepsilon)$.

${ }^{10}$ This ordering can plausibly arise, for example, if "bad loans" are loans to firms that themselves have incentives to destroy value by gambling for resurrection.
} 
As expected, a lower proportion of bad loans, a lower debt level, and a higher recovery upon foreclosure will increase the probability that the bank survives.

We can now write the expected value of equity of a bank that holds bad loans $\theta$ as

$$
\int_{\bar{\varepsilon}_{0}}^{1}(1-\theta+(\theta-\gamma) \varepsilon+\gamma \rho-D) \phi(\varepsilon) d \varepsilon .
$$

As it turns out, the value of equity is convex in $\gamma$ due to the bank's limited liability. It implies that banks are interested in either foreclosing all bad loans or none. In particular, banks with few bad loans want to foreclose all bad loans $(\gamma=\theta)$, and banks with many bad loans foreclose no bad loans $(\gamma=0)$. The intuition for this result is straightforward. Banks that are likely to survive (low $\theta$ ) have a valuation of rolled-over bad loans that is close to their true expected value, and hence prefer to foreclose. Banks that are not very likely to survive (high $\theta$ ) have a valuation of rolled-over bad loans that only reflects their large positive returns in the state in which they survive, and hence do not foreclose. This is the typical gambling for resurrection behavior, and we will therefore refer to the banks that roll over their bad loans (do not foreclose) as gambling banks. We denote as $\hat{\theta}$ the critical value of $\theta$ above which banks will gamble.

Below, we let

$$
\pi_{0}^{G}(\theta)=\int_{1-(1-D) / \theta}^{1}(1-\theta+\theta \varepsilon-D) \phi(\varepsilon) d \varepsilon
$$

denote the value of equity when gambling $\left(\gamma=0\right.$, and hence $\left.\bar{\varepsilon}_{0}=1-(1-D) / \theta\right)$, and

$$
\pi_{0}^{F}(\theta)=\max (1-\theta+\theta \rho-D, 0)
$$

denote the value of equity when foreclosing $(\gamma=\theta)$. In terms of $\pi_{0}^{G}(\theta)$ and $\pi_{0}^{F}(\theta)$, the value of equity, taking into account that banks will choose $\gamma$ optimally, can then be written as

$$
\pi_{0}(\theta)=\max \left(\pi_{0}^{G}(\theta), \pi_{0}^{F}(\theta)\right) .
$$

Figure 1 illustrates this discussion, and Lemma 1 summarizes it formally.

Lemma 1. The value of equity is convex in $\gamma$. As a consequence, a bank with a proportion of bad loans $\theta$ will decide to foreclose an amount $\gamma(\theta)$ given by

$$
\gamma(\theta)= \begin{cases}\theta & \text { if } \theta \leq \hat{\theta} \\ 0 & \text { if } \theta>\hat{\theta}\end{cases}
$$

where $\hat{\theta}$ is defined as the value of $\theta>0$ that solves

$$
\pi_{0}^{F}(\theta)=\pi_{0}^{G}(\theta)
$$




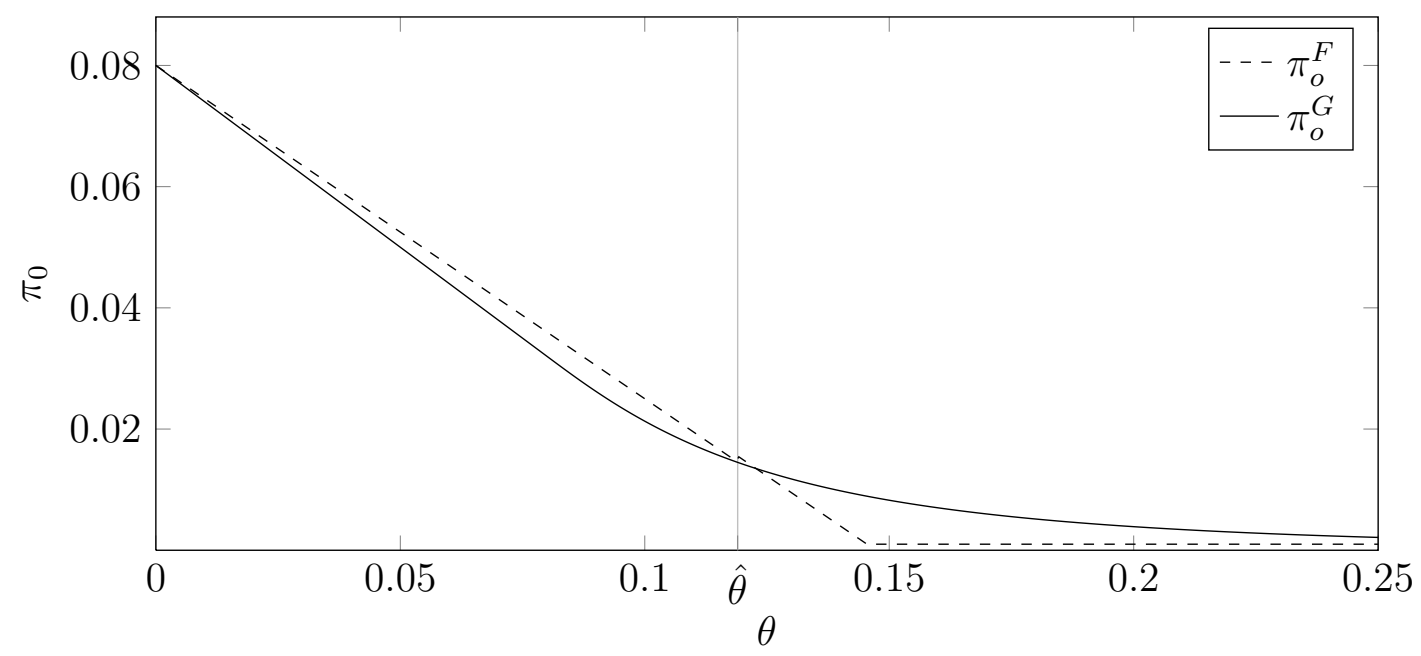

\section{Figure 1: Equity value as a function of $\theta$}

Equity values for banks as a function of $\theta$ when banks foreclose (dashed line, $\pi_{0}^{F}(\theta)$ ), and when banks gamble (solid line, $\pi_{0}^{G}(\theta)$ ). Banks choose whichever is higher. Banks with $\theta>\hat{\theta}$ gamble, and banks with $\theta<\hat{\theta}$ foreclose. Parameters are $1-D=0.08, \rho=0.45$, and $\varepsilon \sim \operatorname{Beta}(2,3)$, which implies $E[\varepsilon]=0.40$.

\section{The regulator's scheme}

In the model described in the previous section, banks that have a large proportion of bad loans have insufficient incentives to foreclose, even though it would be socially optimal for them to do so. There is therefore room for intervention by the regulator aimed at aligning the incentives of these gambling banks with the interests of society.

In this section, we first state the general optimal contracting problem that the regulator faces (Subsection 3.1). Due to the convexity of the bank's objective function, the problem is slightly different from those usually considered in the mechanism design literature. A naive, direct application of standard techniques neither suggests the optimal contract nor provides much useful intuition. For this reason, we will initially restrict ourselves to a specific class of contracts, namely, two-part tariffs, which consist of a subsidy per foreclosed loan and a participation fee (or a price paid per loan transferred to a special purpose vehicle, and a participation fee). The simpler problem of finding the optimal menu of two-part tariffs turns out to be more standard, and an optimal contract can be derived and interpreted (Subsection 3.2). We then show that, in fact, the optimal contract within the class of two-part tariffs also implements the optimal contract for the general problem (Subsection 3.3). 


\section{3..1 The regulator's problem}

We have assumed that the amount foreclosed by a bank, $\gamma$, is observable and contractible. This allows the regulator to transfer resources to the bank contingent on this variable, $T(\gamma) .{ }^{11}$ As usual, given the private information on $\theta$, it is more convenient to consider direct revelation mechanisms under which a bank with type $\theta$ truthfully reports its type, and is then assigned a contract under which it forecloses an amount $\gamma(\theta)$, and in return receives a transfer $T(\theta)$ at $t=2$ if it survives.

Banks facing a menu of contracts will choose the one that maximizes their value of equity. We will denote the value of equity of a participating bank of type $\theta$ that reports type $\theta^{R}$ as $\Pi\left(\theta, \theta^{R}\right)$, given by

$$
\Pi\left(\theta, \theta^{R}\right)=\int_{\bar{\varepsilon}}^{1}\left(1-\theta+\left(\theta-\gamma\left(\theta^{R}\right)\right) \varepsilon+\gamma\left(\theta^{R}\right) \rho-D+T\left(\theta^{R}\right)\right) \phi(\varepsilon) d \varepsilon,
$$

where

$$
\bar{\varepsilon}=\frac{\theta-\gamma\left(\theta^{R}\right) \rho-(1-D)+T\left(\theta^{R}\right)}{\theta-\gamma\left(\theta^{R}\right)} .
$$

Since we consider schemes with voluntary participation, the net transfer $T(\theta)$ for a bank with type $\theta$ will have to be non-negative for that bank to participate, and might have to be positive for that bank to foreclose. This implies that, in general, the scheme will not be costless. We assume that each dollar that the regulator transfers to a bank generates an associated dead-weight loss $\lambda>0$. This loss arises, for example, if in order to finance this scheme the government needs to rely on distortionary taxation. Thus, for a given amount of foreclosed loans, the regulator will be interested in minimizing the cost of the rescue scheme.

We can then state the formal problem as follows:

$$
\max _{\gamma(\theta), T(\theta)} \int_{0}^{1}[1-\theta+\theta E[\varepsilon]+(\rho-E[\varepsilon]) \gamma(\theta)-\lambda(1-\Phi(\bar{\varepsilon})) T(\theta)] \psi(\theta) d \theta,
$$

where $\bar{\varepsilon}$ is given by (8), and subject to

$$
\begin{aligned}
& \Pi(\theta, \theta) \geq \Pi\left(\theta, \theta^{R}\right), \quad \forall \theta, \theta^{R} \\
& \Pi(\theta, \theta) \geq \pi_{0}(\theta), \quad \forall \theta . \\
& \text { and } \quad 0 \leq \gamma(\theta) \leq \theta, \quad T(\theta) \geq 0 .
\end{aligned}
$$

These equations can be interpreted as follows. The objective function, (W), states that the regulator chooses the schedules $\gamma(\theta)$ and $T(\theta)$ to maximize expected welfare. The contribution of a given bank to welfare corresponds to the total value of its assets, which will be

\footnotetext{
${ }^{11} T(\gamma)$ could in principle be negative. This would correspond to a tax on the bank.
} 
divided between its equity holders and debt holders at $t=2$, net of the (expected) deadweight loss associated with the transfers it receives. ${ }^{12}$ The total value of the bank's assets are maximized when it forecloses. The main trade-off here is therefore between inducing foreclosure in order to maximize the value of assets, versus the deadweight loss associated with the transfers that induce foreclosure. In Section 4 we consider alternative social welfare functions.

The menu of contracts that the regulator offers has to induce banks to truthfully report their type, producing the incentive compatibility constraint, (IC). It also has to lead to a higher value of equity than when not participating, producing the participation constraint $(\mathrm{PC})$.

This problem is somewhat non-standard because the objective function of a bank is convex in $\gamma$. A standard method (the so-called first-order approach) for working out the optimal contract would first point out that for banks with more bad loans, it is more painful to foreclose a given amount of bad loans. ${ }^{13}$ This would then suggest that to distinguish between banks, an optimal contract would make banks with more bad loans foreclose less. This, however, ignores the fact that because of the convexity, it is actually easier to convince banks to foreclose all of their bad loans than only some of them. (The reasons for the convexity are of course limited liability, and the fact that rolling over bad loans delays the resolution of uncertainty, which are also the two features that drive the gambling behaviour of banks.)

For this reason, we first restrict ourselves to two-part tariffs in a way that emphasizes the point at which banks foreclose all of their bad loans. As it turns out, this makes it easier to identify the optimal contract, and to understand the underlying intuition. For ease of exposition, we will initially only focus on the "foreclosure subsidy" version of the two-part tariff.

\section{$3 . .2$ A menu of two-part tariffs}

Consider the following alternative scheme: Suppose the regulator offers a menu of two-part tariffs, where each two-part tariff consists of (i) a subsidy $s$ that the bank receives per loan that it forecloses, and (ii) a participation fee $F$ that the bank promises to pay if it survives. Banks do not have to commit to foreclosing a specific amount, and can privately choose how

\footnotetext{
${ }^{12}$ Notice that the way we have expressed this, the transfer is only paid if the bank survives. Such a contract would obviously minimize the social cost of the transfer. In the optimal contract below, participating banks will always survive in any case.

${ }^{13}$ This is because banks compare the recovery obtained when foreclosing against the expected return when rolling over, conditional on survival. The less likely a bank is to survive, the higher this expected return conditional on survival, and the more painful it is to foreclose.
} 
many loans they want to foreclose. In this scheme, the role of the subsidy will be to induce banks to foreclose, and the role of the fee will be to claw back (some or all of) the increase in the value of equity of a bank that is derived from the subsidy.

As before, it is more convenient to consider direct revelation mechanisms under which a bank with type $\theta$ is meant to truthfully reports its type and then receive the contract $(s(\theta), F(\theta))$. In terms of this notation, a bank that reports a type $\theta^{R}$ commits to a fixed fee $F\left(\theta^{R}\right)$ in return for a subsidy $s\left(\theta^{R}\right)$ per foreclosed loan, and receives a net transfer $T(\gamma)=s\left(\theta^{R}\right) \gamma-F\left(\theta^{R}\right)$, that indirectly depends on the amount $\gamma$ that the bank chooses to foreclose under the tariff.

It is natural to consider subsidies $s$ that are positive, and vary between 0 and $1-\rho$. As a result, the value of foreclosing a bad loan to a participating bank may vary between $\rho$ and face value, 1 . Allowing for a subsidy greater than $1-\rho$ would lead to banks obtaining more than face value from foreclosed bad loans - but since the best they can obtain from a bad loan if they gamble is face value, such a large subsidy will never be necessary. Similarly, it is natural to consider fees $F$ that are positive, and vary between 0 and $1-D$. All banks would be happy to participate at a zero fee, and no bank will want to participate at a fee that exceeds $1-D$, the maximum possible value that equity can attain after having foreclosed all bad loans.

Consider a gambling bank, that is a bank with a proportion of bad loans $\theta>\hat{\theta}$, that decides to participate in the scheme and picks the contract indexed by $\theta^{R}$, and that subsequently forecloses a share $\gamma$ of bad loans. In that case, the counterpart of the expected value of equity (7) under this scheme is

$$
\max _{\gamma} \int_{\bar{\varepsilon}(\gamma)}^{1}\left(1-\theta+(\theta-\gamma) \varepsilon+\gamma\left(\rho+s\left(\theta^{R}\right)\right)-D-F\left(\theta^{R}\right)\right) \phi(\varepsilon) d \varepsilon,
$$

where

$$
\bar{\varepsilon}(\gamma)=\frac{\theta-\gamma\left(\rho+s\left(\theta^{R}\right)\right)-\left(1-D-F\left(\theta^{R}\right)\right)}{\theta-\gamma} .
$$

As before, it is easy to see that the value of equity is convex in $\gamma$ leading to a corner solution. Under the scheme the bank will either foreclose all of its bad loans $(\gamma=\theta)$ or not foreclose any $(\gamma=0)$. Foreclosure leads to a higher value of equity if

$$
1-\theta+\left(\rho+s\left(\theta^{R}\right)\right) \theta-D-F\left(\theta^{R}\right) \geq \int_{\bar{\varepsilon}(0)}^{1}\left(1-\theta+\varepsilon \theta-D-F\left(\theta^{R}\right)\right) \phi(\varepsilon) d \varepsilon .
$$

Notice that a necessary condition for a bank to be willing to foreclose is that the transfer $F$ is sufficiently small (or $s$ sufficiently large) for the bank to survive, since gambling always produces a non-negative value of equity. 
Suppose that (11) is satisfied and the bank forecloses. We can now compare the value of equity from participating and foreclosing, and the value of equity from not participating and gambling. A bank would want to participate with the contract indexed by $\theta^{R}$ if

$$
1-\theta+\left(\rho+s\left(\theta^{R}\right)\right) \theta-D-F\left(\theta^{R}\right) \geq \underbrace{\int_{\bar{\varepsilon}_{0}}^{1}(1-\theta+\varepsilon \theta-D) \phi(\varepsilon) d \varepsilon}_{\pi_{0}^{G}(\theta)} .
$$

Comparing (12) and (11), we can see that as long as $F\left(\theta^{R}\right)>0,(12)$ implies (11). Intuitively, a bank will never want to participate just to pay a positive fee, and not receive any subsidy in return. A participating bank will therefore always foreclose.

This allows us to rewrite the value of equity of a bank with type $\theta$ that participates (and hence forecloses) and picks the contract indexed by $\theta^{R}$ as

$$
\Pi\left(\theta^{R}, \theta\right)=1-\theta+\left(\rho+s\left(\theta^{R}\right)\right) \theta-D-F\left(\theta^{R}\right) .
$$

The participation constraint (PC) and the incentive compatibility constraint (IC) for the two-part tariff case can now be stated in terms of this expression.

Because banks that participate always foreclose, the expression for the value of equity of a participating bank is simplified substantially. For this reduced problem, applying the standard first-order approach produces much more meaningful results.

In the rest of our discussion, it will be convenient to denote as $U(\theta)$ the increase in the value of equity that a bank obtains when it participates and chooses the contract intended for its type, over the value of equity when it does not participate. That is,

$$
U(\theta)=\Pi(\theta, \theta)-\pi_{0}(\theta)
$$

This expression can be interpreted as the information rents that a bank obtains from participating in the scheme. Obviously, for a bank with type $\theta$ to participate, $U(\theta) \geq 0$.

Inserting the expression for $\Pi(\theta, \theta)$ we can also express the information rents as

$$
U(\theta)=\underbrace{s(\theta) \theta-F(\theta)}_{T(\theta)}-\underbrace{\left(\pi_{0}(\theta)-(1-\theta+\theta \rho-D)\right)}_{\Delta \pi_{0}(\theta)} .
$$

In words, this states that the information rents of a bank with type $\theta$ will consist of the net transfer it receives, minus the decrease in the value of equity associated with now taking the privately non-optimal action, foreclosing. Below, we will refer to $\Delta \pi_{0}(\theta)$ as the loss from foreclosing. 
Notice that in the expression for $\Delta \pi_{0}(\theta)$, the part $1-\theta+\theta \rho-D$ may be negative. That is, we are here defining the loss from foreclosing that a bank would bear if the transfer is simultaneously large enough to ensure that it survives, and the fact that the bank is operating under limited liability is not relevant. Of course, if a bank is to participate under the scheme, the transfer will have to be large enough to ensure that it survives, so this is the relevant case to consider.

The loss from foreclosing plays an important role below because it indicates a critical size of the net transfer: When the net transfer is equal to the loss from foreclosing, banks are exactly as well off when participating as when not participating. It is easy to see that the loss from foreclosing is zero for $\theta<\hat{\theta}$, and positive, increasing and convex in $\theta$ for $\theta>\hat{\theta}$ - by limited liability, $\pi_{0}^{G}(\theta)$ is convex and bounded below by 0 , whereas the second term decreases linearly.

We can now state necessary and sufficient conditions for incentive compatibility to hold locally and globally, in terms of the information rents.

Lemma 2. Necessary and sufficient conditions for a two-part tariff scheme $\{s(\theta), F(\theta)\}$ to be incentive compatible are

i) monotonicity: $s(\theta)$ is non-decreasing.

ii) local optimality:

$$
\frac{d U(\theta)}{d \theta}=s(\theta)-\frac{\partial \Delta \pi_{0}(\theta)}{\partial \theta}
$$

The proof for these conditions, although sketched in the appendix for completeness, is standard. The first part of Lemma 2 can be interpreted as stating that banks with more bad loans should receive higher subsidies under an implementable scheme. Intuitively, banks with more bad loans care more about the size of the subsidy, and hence in any incentive compatible scheme will have to receive higher subsidies. Of course, the higher subsidies will need to be associated with higher fees. Under a scheme that provides a higher subsidy against payment of a higher fee, banks with a low proportion of bad loans will then choose to pay a low fee and receive a low subsidy, whereas banks with a high proportion of bad loans will choose to pay a high fee and receive a high subsidy.

The second part of Lemma 2 can be interpreted as stating that to induce truth-telling, the regulator has to provide information rents that vary with the proportion of bad loans $\theta$. The two components of the expression reflect two countervailing incentives that banks face, to both overstate as well as understate their type, which change with $\theta$, as we now describe. ${ }^{14}$

\footnotetext{
${ }^{14}$ The term countervailing incentives was first coined by Lewis and Sappington (1989).
} 
First, suppose the loss from foreclosing $\Delta \pi_{0}(\theta)$ were constant, such that the second term in (16) would be zero for all $\theta$. Then, since the subsidy $s(\theta)$ must be positive, information rents $U(\theta)$ would have to be higher for banks with higher $\theta$. This is because banks with high $\theta$ would otherwise understate their type, to pretend that they benefit less from the positive subsidy and in this way manage to pay a lower fee to the regulator. This incentive to understate is stronger the larger is $s(\theta)$.

Second, suppose the subsidy $s(\theta)$ were zero for all $\theta$. Then, since the loss from foreclosing $\Delta \pi_{0}(\theta)$, is increasing in $\theta$ (for $\theta>\hat{\theta}$ ), information rents $U(\theta)$ would have to be higher for banks with lower $\theta$. This is because banks with low $\theta$ would otherwise overstate their type, to pretend that they are incurring larger losses from foreclosing and in this way manage to pay a lower fee to the regulator. This incentive to overstate is larger the larger is $\frac{d \Delta \pi_{0}(\theta)}{d \theta}$.

The incentives to overstate and understate are in conflict, of course. A regulator that is interested in minimizing the cost of the scheme can try to pick a $s(\theta)$ that plays off the incentives for banks to overstate against the incentives to understate, in order to reduce information rents, subject to the constraints that $s(\theta)$ needs to be increasing, and $U(\theta)$ cannot be negative.

It turns out that since $\partial \Delta \pi_{0}(\theta) / \partial \theta$ is an increasing function of $\theta$ we can pick an increasing function $s(\theta)$ that plays off the incentives to understate and overstate such that they exactly cancel out, and leave information rents constant. In order to minimize information rents, the regulator can then pick the constant level as $U(\theta)=0 .{ }^{15}$

The following proposition describes the optimal menu of contracts that results from the previous discussion and satisfies the necessary and sufficient conditions for incentive compatibility of Lemma 2, as well as the participation constraint $U(\theta) \geq 0$ :

Proposition 1. For $\theta \in[\hat{\theta}, 1]$, consider the menu of two-part tariffs $\left\{s^{*}(\theta), F^{*}(\theta)\right\}$, where

$$
\begin{aligned}
s^{*}(\theta) & =\frac{\partial \Delta \pi_{0}(\theta)}{\partial \theta} \\
F^{*}(\theta) & =-\Delta \pi_{0}(\theta)+\theta s^{*}(\theta) .
\end{aligned}
$$

Under this menu, any bank with a proportion of bad loans $\theta$ will choose the corresponding contract $\left(s^{*}(\theta), F^{*}(\theta)\right)$, foreclose the amount $\gamma=\theta$, and satisfy its participation constraint with strict equality.

\footnotetext{
${ }^{15}$ This is a special case of the argument of Maggi and Rodríguez-Clare (1995) who point out that, in general, decreasing convex outside opportunities can lead to optimal contracts that eliminate information rents for a range of agents.
} 
What are the fundamental features of the model that make this two-part tariff scheme work? The scheme works because the difference in the values of equity when gambling and not gambling is convex in $\theta$, which means that a scheme that pays higher subsidies to banks with more bad loans can play off the incentives to overstate and understate such that they exactly cancel out. This convexity in turn is produced by limited liability and the fact that rolling over bad loans delays the resolution of uncertainty. Since these were the two features that led to the gambling behavior in the first place, it is therefore likely that in any model in which banks gamble for resurrection because of limited liability, countervailing incentives will allow the regulator to eliminate (or substantially reduce) the information rents.

The subsidies here will start at a low positive value, and then increase up to $s^{*}(1)=1-\rho$, which means that banks with a proportion of bad loans close to 1 will receive essentially face value for their foreclosed loans. Similarly, fees will start at a low positive value, and then increase up to $F^{*}(1)=1-D$, which means that banks with a proportion of bad loans close to 1 will have to give up essentially the entire equity value $1-D$, since without participating, their equity value is essentially zero.

\section{3..3 The general solution to the regulator's problem}

Under the two-part tariff scheme, banks always foreclose all of their bad loans, and they receive a transfer that just offsets the loss from foreclosing. This suggests a candidate solution for the general problem of $\gamma^{*}(\theta)=\theta$, and $T^{*}(\theta)=\Delta \pi_{0}(\theta)$, so that banks foreclose all their bad loans in exchange for a payment that just covers their participation constraint.

Considering only the integrand of $(\mathrm{W})$, we can see that the benefit from getting a bank with type $\theta$ to foreclose any amount is always maximized when it forecloses the maximum amount, $\gamma^{*}(\theta)=\theta$. Similarly, the cost of getting a bank to foreclose any amount, $T(\theta)$ is always minimized when $T(\theta)=\Delta \pi_{0}(\theta){ }^{16}$

But since $\Delta \pi_{0}(\theta)$ is increasing and strictly convex in $\theta$ for banks with $\theta>\hat{\theta}$ that gamble, it is possible that the social cost $\lambda T(\theta)$ of getting a bank with a large proportion of bad loans $\theta$ to foreclose is larger than the benefit $(\rho-E[\varepsilon]) \theta$, which is increasing and linear in $\theta$. This suggests that there will be an upper limit, that we denote as $\theta^{*}$, of the proportion of bad loans for which banks should be made to foreclose.

Proposition 2. The optimal contract $\left\{\gamma^{*}(\theta), T^{*}(\theta)\right\}$ that solves (W) subject to (IC) and

\footnotetext{
${ }^{16}$ Note that $\Delta \pi_{0}(\theta)=0$ for banks with $\theta<\hat{\theta}$, since such banks are willing to foreclose on their own, and no transfer is necessary.
} 
$(\mathrm{PC})$ is given by

$$
\gamma^{*}(\theta)=\left\{\begin{array}{ll}
\theta & \text { for } \theta \leq \theta^{*} \\
0 & \text { for } \theta>\theta^{*}
\end{array}, \quad T^{*}(\theta)=\left\{\begin{array}{ll}
\Delta \pi_{0}(\theta) & \text { for } \theta \leq \theta^{*} \\
0 & \text { for } \theta>\theta^{*}
\end{array},\right.\right.
$$

where $\theta^{*}$ solves

$$
(\rho-E[\varepsilon]) \theta^{*} \equiv \lambda \Delta \pi_{0}\left(\theta^{*}\right)
$$

It is obvious that this contract satisfies the participation constraint (PC). A formal proof that this contract also satisfies the incentive compatibility constraint (IC) is in the appendix. Intuitively, if a bank were to report and hence foreclose slightly less than its true proportion of bad loans, this would mean receiving a lower transfer (since $T^{*}(\theta)$ is increasing in $\theta$ ), as well as reducing the value of equity, since it is convex in the amount of foreclosed loans. This means that it is always worse off than when reporting its true proportion of bad loans. ${ }^{17}$

Many schemes that can implement the optimal contract in Proposition 2 can be considered. For example, although maybe not the main focus of their paper, Aghion, Bolton, and Fries (1999) also propose a scheme that can be interpreted as an alternative way of implementing the optimal contract here, although they do not study which features of the problem allow information rents to be eliminated. In their model, banks can have four different types (proportions of bad loans), and banks with the highest two types want to gamble. They show that a particular scheme that pays a foreclosure subsidy that is non-linear in the proportion of bad loans can induce both gambling types to foreclose, without paying information rents to either.

This can be translated into the terms of our model as follows: Consider a subsidy $z(x)$ that is received for foreclosing the additional, infinitesimal amount of bad loans $d x$, where $z(x)$ varies with amount of foreclosed loans as given by

$$
\int_{0}^{\gamma} z(x) d x \equiv \Delta \pi_{0}(\gamma)
$$

so that

$$
z(x)=\frac{d \Delta \pi_{0}(x)}{d x}
$$

Since the subsidy associated with foreclosing an amount $\gamma, \int_{0}^{\gamma} z(x) d x$, is non-concave in $\gamma$ the value of equity when participating would still be convex, and banks would either foreclose all bad loans, or no bad loans. But by construction, banks are again indifferent between

\footnotetext{
${ }^{17}$ So far, we have not considered the case in which the bank can pretend to have a higher proportion of bad loans than it actually has. For this case, see Section 4.
} 
foreclosing all bad loans or none. Under this subsidy, banks therefore participate, foreclose all bad loans, and satisfy their participation constraint with equality. Hence, this is another way of implementing the optimal contract.

Another alternative implementation would be an asset buyback variant of the two-part tariff that we consider in Subsection 3.2. Suppose that a bank that reports a type $\theta^{R}$ commits to pay a fixed fee $F\left(\theta^{R}\right)$, in return for a price $p\left(\theta^{R}\right)$ per loan that it sells to the regulator. The regulator forecloses all loans that it buys. Following the argument in Subsection 3.2, the participation profits for a bank reporting type $\theta^{R}$ under this implementation are

$$
\Pi\left(\theta^{R}, \theta\right)=1-\theta+p\left(\theta^{R}\right) \theta-D-F\left(\theta^{R}\right),
$$

and the information rents of a bank that truthfully reports its type can be expressed as

$$
U(\theta)=p\left(\theta^{R}\right) \theta-F\left(\theta^{R}\right)-\left(\pi_{0}(\theta)-(1-\theta-D)\right) .
$$

The menu of two-part tariffs $\left\{p^{*}(\theta), F^{*}(\theta)\right\}$ under which any bank with a proportion $\theta$ will choose the right contract, foreclose all bad loans, and satisfy its participation constraint with strict equality, corresponding to the menu of contracts in Proposition 1, is given by

$$
\begin{aligned}
p^{*}(\theta) & =\frac{\partial}{\partial \theta}\left(\pi_{0}(\theta)-(1-\theta-D)\right) \\
F^{*}(\theta) & =-\left(\pi_{0}(\theta)-(1-\theta-D)\right)+\theta p^{*}(\theta) .
\end{aligned}
$$

This implementation has as a main advantage over the foreclosure subsidy discussed in Subsection 3.2 that neither $p^{*}(\theta)$ nor $F^{*}(\theta)$ depend on $\rho$. We discuss situations in which this can be important in the next section.

\section{Extensions and Robustness}

In this section, we discuss how robust the results in the previous section are to changes in some of our assumptions. In particular, we discuss the possibility of banks foreclosing good loans (Subsection 4.1), how versions of the scheme could be implemented if the regulator knew less than we assumed (Subsection 4.2), how deposit insurance, a social cost of bank failure, and potential bank runs would affect the welfare trade-off (Subsection 4.3), and we also compare our voluntary scheme to mandatory schemes, and discuss ex-ante moral hazard (Subsection 4.4). 


\section{4..1 Foreclosing good loans}

So far, we have assumed that banks can only foreclose bad loans. This is a realistic assumption if one thinks that bad loans are loans on which some default has occurred, and good loans are loans on which no default has occurred. In this case, there would be a legal basis only for foreclosing bad loans.

One can think of a situation, however, in which some good loans are in "technical default", that is, in a situation in which a financial covenant other than that requiring the timely payment of interest or principal is breached. For example, loan contracts can stipulate that a firm maintain a minimum current ratio - if the current ratio falls below this level, the contract is breached. ${ }^{18}$ Such covenants are used in many loan contracts, are typically set very tight, and are hence frequently violated. Chava and Roberts (2008) for example report that in their sample, about $15 \%$ of borrowers are in technical default at any point in time. Once a firm is in technical default, the bank has the right to foreclose, although in "normal circumstances" banks typically would not exercise this right.

In this subsection, we discuss to what extent our optimal contract is robust to a situation in which banks can also foreclose good loans - a bank might want to do so to pretend to be of a worse type, and hence receive higher transfers. In other words, we discuss to what extent our optimal contract is still incentive compatible when good loans can be foreclosed.

Suppose initially that we are talking about an implementation of the scheme in which the bank is paid a subsidy to foreclose a loan, and that the return from a foreclosed loan accrues to the bank (this is in line with our discussion in Section 3). Suppose that foreclosing a good loan produces a return $\rho_{G}$, potentially different from the return obtained when foreclosing a bad loan, $\rho$.

We also assume that $\rho_{G}<1$, so that foreclosing good loans is costly. As a result, banks would never foreclose good loans in the absence of a scheme. This is because, conditional on survival, the change in the value of equity from foreclosing an additional good loan $\rho_{G}-1$ is always negative. In contrast, conditional on survival, the change in the value of equity from foreclosing an additional bad loan $\rho-E[\varepsilon \mid \varepsilon>\bar{\varepsilon}]$ is positive if the firm is likely to survive, and negative if it is likely to fail - this is the source of the gambling incentives (here, $\bar{\varepsilon}$ denotes the relevant threshold return on bad loans that is necessary for the bank to survive).

In the presence of a scheme, however, things are not so clear. When a transfer is contingent on foreclosing a certain quantity of loans, and a regulator cannot distinguish between a foreclosed good loan and a foreclosed bad loan, a bank might choose to foreclose some good

\footnotetext{
${ }^{18}$ The current ratio is defined as the ratio of current assets to current liabilities.
} 
loans in addition to or instead of its bad loans, to obtain a higher transfer.

If a bank is targeting a given transfer and therefore has to foreclose a given amount of loans, it will foreclose good loans if the opportunity cost of doing so is lower than the cost of foreclosing bad loans. That is, if

$$
E[\varepsilon \mid \varepsilon>\bar{\varepsilon}]-\rho>1-\rho_{G},
$$

or

$$
\rho_{G}-\rho>1-E[\varepsilon \mid \varepsilon>\bar{\varepsilon}] .
$$

We show in Appendix B that if $\rho_{G}-\rho$ is positive and "large enough", banks may have incentives to foreclose good loans to overstate their type and receive higher transfers. In this case, our optimal contract would not be incentive compatible. Conversely, if $\rho_{G}-\rho$ is positive but "small enough", or non-positive, banks do not have incentives to overstate their type, and our optimal contract is incentive compatible.

The value of equity when foreclosing good loans is always increasing in the reported type (as long as the reported type receives a positive transfer under the scheme). This means that banks only consider foreclosing good loans if the value of equity they obtain from pretending to be of the "highest possible type" exceeds the value of equity from reporting truthfully. This determines the critical upper limit for $\rho_{G}-\rho$. The "highest possible type" might be determined by the maximum number of good loans that can be foreclosed because they are in technical default, or by $\theta^{*}$, the highest type that still receives a positive transfer under our scheme.

It is worth noting, however, that if the scheme is implemented as an asset buyback as discussed above, banks will never have incentives to overstate their type. Intuitively, this happens because under an asset buyback, the return when a loan is foreclosed accrues to the regulator, and not to the bank. Therefore, even if $\rho_{G}>\rho$, the bank does not benefit from the higher return on the good loan when foreclosing this instead of a bad loan, but the regulator does. Under a buyback implementation, banks therefore do not have incentives to sell good loans.

\section{4..2 A regulator with less information}

In this subsection, we discuss to what extent our scheme would still work if the regulator had less information than we assumed so far, on both $\rho$, the return on bad loans if foreclosed, and the distribution of $\varepsilon$. 
Consider first the case in which the regulator does not know $\rho$. That is, banks could potentially have an informational advantage with respect to $\rho$ as well as $\theta$. Since our foreclosure subsidy implementation of the optimal contract requires knowledge of $\rho$ (to calculate $\Delta \pi_{0}(\theta)$ ), this would present a problem. However, as pointed out in Subsection 3.3, the asset buyback implementation of the optimal contract does not require such knowledge. Intuitively, when deciding whether or not to gamble, banks only compare the value of equity when gambling with the value of equity when participating in the scheme. Under an asset buyback implementation, the first depends on the distribution of $\varepsilon$, and the second only depends on the price per bad loan afforded by the scheme, but neither depend on $\rho$. A buyback implementation would therefore be robust even to a situation in which $\rho$ differed across bad loans, and/ or banks had private information on $\rho$, in the sense that bad loans can still be removed from banks' balance sheets and foreclosed.

However, for the welfare function that we have considered so far, it is only the increase in net present value of $\rho-E[\varepsilon]$ from foreclosing a bad loan that produces a social benefit of foreclosing. If the regulator does not know $\rho$, it is possible that the regulator does not in fact know whether a scheme that induces foreclosure necessarily increases net present value and hence welfare. Unless there are additional social benefits from foreclosing (see below), a regulator might then not want to set up a scheme that induces foreclosure. ${ }^{19}$

Now consider the case in which the regulator does not know the true distribution of $\varepsilon$. A problem with our scheme then is that it always requires knowledge of the non-participation value of equity, which in turn requires knowledge of the value of gambling, and hence the distribution of $\varepsilon$. As a result, under our two-part tariff implementation without private information, a high (low) fee would be optimal when the value of gambling is low (high). Hence, if the distribution of $\varepsilon$ is not known, the regulator might need to trade-off a lower probability that the contract is accepted with the costly rents that might accrue to bank equity holders that benefit from the low.

In this context, it is possible that certain auction designs could help in setting the fees. In the buyback implementation, one can interpret the transaction in which a bank obtains the right to sell an unlimited quantity of bad loans at a given price in exchange for the participation fee as the purchase of a put option. Instead of selling these put options, they could be auctioned off. The idea is that banks would bid up the fees for the various options, and in doing so, reveal the value that they attach to the options (and hence the value they attach to gambling, and about the distribution of $\varepsilon$ ). It is easy to show that in the context of

\footnotetext{
${ }^{19}$ In this case, if $\rho$ was contractible, one could still think of versions of our scheme that ensure that only net present value enhancing foreclosure takes place.
} 
our model, the bank that attaches the highest value to the right to sell bad loans at a given price would be the bank that is meant to sell at that price under our scheme, and for which a tangency condition as in (25) would be satisfied.

If an auction manages to allocate any given option to the bank that attaches the highest value to that option, and due to competition, the auction manages to extract most of the surplus, then it would be yet another way to implement something very close to our optimal contract, with the important difference that the regulator would not need to know the distribution of $\varepsilon$. There are two issues, though. First, ensuring a sufficient amount of competition in the auction is likely to be difficult, especially if the regulator would prefer all banks to participate in the scheme. Second, the regulator would need to have at least some minimum knowledge of the distribution of $\varepsilon$ in order to determine the range of strike prices for which options should be auctioned off. A full discussion of an appropriate auction design is likely to be interesting, but beyond the scope of this paper.

\section{4..3 Alternative welfare functions}

In this subsection we discuss several variations of the social welfare function we have postulated in the main text. In particular, we consider how the existence of deposit insurance, a social cost of bank failure, and the possibility of systemic risk or bank runs affect the welfare trade-off.

In our base model, bank equity holders do not benefit from the scheme, but bank debt holders do benefit from the scheme. This is because bank debt becomes safe once banks stop gambling. The positive transfer that is necessary to induce to banks to stop gambling is in fact an implicit transfer to debt holders. However, if the regulator already has some preexisting commitments to make transfers to debt holders if a bank defaults (which can only happen when the bank gambles), then the incremental (expected) transfer to debt holders implied by the scheme over and above the expected transfers from pre-existing commitments, and hence the true incremental cost of the scheme, is lower.

Deposit insurance is such a pre-existing commitment to make transfers to (some) debtholders in the case of bank default. Suppose that insured deposits make up a fraction $\alpha \in[0,1]$ of total bank debt $D$ and that, for simplicity, $\alpha$ is the same across all banks. Assume that deposits are senior to other forms of debt, as is likely to be the case in practice, such that the regulator has to make insurance payments only if the remaining assets of a defaulting bank are less than $\alpha D$. The expected deposit insurance cost associated with a bank with a 
proportion of bad loans $\theta$ that does not participate and decides to gamble is

$$
D I(\theta)=\int_{0}^{\bar{\varepsilon}_{D I}}[\alpha D-(1-\theta+\theta \varepsilon)] \phi(\varepsilon) d \varepsilon,
$$

where $\bar{\varepsilon}_{D I}$ is the highest value of $\varepsilon$ for which the remaining assets of the bank are not enough to repay $\alpha D$. That is,

$$
1-\theta+\theta \bar{\varepsilon}_{D I}=\alpha D
$$

It is immediate that

$$
\begin{aligned}
D I^{\prime}(\theta) & =\int_{0}^{\bar{\varepsilon}_{D I}}(1-\varepsilon) \phi(\varepsilon) d \varepsilon>0, \\
D I^{\prime \prime}(\theta) & =\left(1-\bar{\varepsilon}_{D I}\right) \phi\left(\bar{\varepsilon}_{D I}\right) \frac{1-\alpha D}{\theta^{2}}>0,
\end{aligned}
$$

so that the cost of deposit insurance increases in $\theta$ more than linearly.

If we take into account this new element, the incremental social cost of funds of the scheme we described in the previous sections will now become $\lambda(T(\theta)-D I(\theta))$, since $D I(\theta)$ is a preexisting commitment. Given that in our two-part tariff argument nothing relies on the social cost of funds, it is easy to see that the same combinations $\left\{s^{*}(\theta), F^{*}(\theta)\right\}$ will allow inducing foreclosure by any targeted bank, and keep it to its participation constraint. Similarly, in the general case, the optimal mechanism will be given by the corresponding $\left\{\gamma^{*}(\theta), T^{*}(\theta)\right\}$.

There will be a change, however, in the decision as to which banks should participate. In particular, it is not necessarily true that the regulator will make banks with a low proportion of bad loans participate, and let banks with a high proportion of bad loans gamble, with the marginal type determined by an equation such as (20).

This is because the cost of making a bank participate, $\lambda\left[\Delta \pi_{0}(\theta)-D I(\theta)\right]$, is now not necessarily convex in $\theta$. Depending on the exact shape of $D I(\theta)$, which depends on $\alpha$ and the distribution of $\varepsilon$, it is possible, for example, that the regulator will make banks with low and high proportions of bad loans participate, but let those with medium proportions gamble. This could arise if the expected deposit insurance costs on banks with a medium proportion of bad loans were low, but the expected deposit insurance costs for banks with a high proportion of bad loans were high.

We now turn to another possible source of social benefit from making banks foreclose bad loans. Bank failure might be costly per se from a social point of view. Assume that there is a constant social cost $B>0$ that is incurred whenever a bank fails which, for simplicity, is independent of the proportion of failed banks. ${ }^{20}$ Now, making a bank participate and

\footnotetext{
${ }^{20} \mathrm{~A}$ much more complicated version of the welfare function would arise if $B$, the social cost of bank failure, were to depend on the number of failing banks - as it plausibly might if the regulator is worried about an element of systemic risk.
} 
foreclose not only leads to an increase in social welfare derived from efficient foreclosure of the bad loans, $(\rho-E[\varepsilon]) \theta$, but also to an increase in social welfare derived from the reduction of the probability of bank failure to zero. The expected social cost of bank failure of bank failure is reduced from $B \Phi(\bar{\varepsilon})$ to 0 .

Again, the way in which banks can be induced to foreclose does not change. There will be a change, however, in the decision as to which banks should participate. Again, it is now not in general true that the regulator will make banks with a low proportion of bad loans participate, and let banks with a high proportion of bad loans gamble, with a marginal type determined by an equation such as (20).

This is because, the total social benefit of making a bank with type $\theta$ foreclose is now $(\rho-E[\varepsilon]) \theta+B \Phi(\bar{\varepsilon})$, which is not linear in $\theta$. Depending on the exact shape, it is possible, for example, that the regulator will make banks with a low and high proportion of bad loans participate, but let those with medium proportions gamble. This could arise if, absent any intervention, the probability of bank failure for banks with a high proportion of bad loans is very high, so that the regulator will make such banks participate to ensure that they do not fail.

Regulators might be also concerned with the possibility of bank runs, which our base model has abstracted from. Consider, for instance, a scenario in which banks are brought down by a bank run when their probability of default at $t=2$, call it $q$, is above a certain threshold $\bar{q}$, and suppose that this produces a social cost. In our context, the decision of a bank to participate reveals information about the probability of failure of that bank. That is, if a bank participates, the probability of failure becomes 0. However, for banks that do not participate, depositors cannot distinguish whether this is because the bank was safe before (in our context, $\theta \leq \hat{\theta}$ ), or because the bank is in such a dire condition that participation is not profitable (in our context, $\theta>\theta^{*}$ ). As a result, depositors would calculate a probability of default conditional on a bank not participating, $q_{D}$, as

$$
q_{D}=\frac{\int_{\theta^{*}}^{1} \Phi\left(\bar{\varepsilon}_{0}\right) \psi(\theta) d \theta}{1-\Psi\left(\theta^{*}\right)+\Psi(\hat{\theta})},
$$

where $\bar{\varepsilon}_{0}$ is obtained from (2). If it turns out that $q_{D}>\bar{q}$, banks that do not participate would be brought down by a bank run. ${ }^{21}$ The regulator can potentially prevent this situation and increase social welfare by changing which banks do and do not participate in the scheme. This would give an additional criterion for selecting the banks that participate in the scheme.

\footnotetext{
${ }^{21}$ This could plausibly arise in a bank run model based on a global game (Goldstein and Pauzner, 2005), where the probability of default plays the role of the "fundamental", and whether or not a bank participates in a scheme is public information.
} 
However, as in Philippon and Skreta (2010), the non-participation value of equity would then be endogenous, which would complicate the mechanism design problem.

\section{4..4 Mandatory schemes and ex-ante incentives}

Above, we derive the optimal scheme with voluntary participation that prevents banks from gambling for resurrection when the proportion of bad loans on a bank's balance sheet is private information of that bank. We have argued that the focus on schemes with voluntary as opposed to mandatory participation is useful, because schemes with mandatory participation are often politically infeasible.

Nevertheless, one can ask whether it is possible to consider schemes with mandatory participation in our basic setup. The answer is that this is possible, but not necessarily meaningful: Suppose that banks cannot refuse to participate in a scheme, but that limited liability puts a lower limit of zero on the participation value of equity. This means that our participation constraint (PC) would no longer be relevant, and that a limited liability constraint stating that $\Pi(\theta, \theta) \geq 0$ would take its place. Thus, $T(\theta)$ could now be negative. From direct consideration of the regulator's problem, it can be shown that the optimal contract in this case would be

$$
\left\{\gamma^{*}(\theta)=\theta, \quad T^{*}(\theta)=-(1-\theta+\theta \rho-D)\right\} .
$$

By construction, the transfer $T^{*}(\theta)$ implies that the participation profits are $\Pi(\theta, \theta)=0$. Since bank shareholders end up with nothing under the optimal mandatory scheme, this means that the optimal mandatory contract in our model is the effective nationalization of all banks. It can also easily be checked that this contract satisfies (IC). Since bank shareholders of all banks will be expropriated, banks have no incentives to lie about their proportion of bad loans.

The reason that the optimal contract in this case is so drastic is that our model abstracts from the effect that such a nationalization threat would have on the ex-ante incentives of banks. One could imagine, for instance, a model in which exerting costly effort to screen investment projects at a date $t=0$ produces an improvement (in the first-order-stochastic dominance sense) in the distribution from which a bank draws its $\theta$ at $t=1$ (Aghion, Bolton, and Fries, 1999). If bank shareholders receive nothing ex-post, regardless of the amount of effort exerted, then obviously, the optimal choice of effort is zero.

A regulator that worries about such ex-ante incentives would ideally like to punish only the banks that end up having a large proportion of bad loans (and potentially reward banks 
that end up having a small proportion of bad loans). The value of equity when participating in a scheme should probably be decreasing in the proportion of bad loans in order to induce effort in selecting loans.

Under voluntary schemes, the rate at which the value of equity when participating in a scheme decreases in the proportion of bad loans is limited by the non-participation values of equity (unless banks with a small proportion of bad loans are to be rewarded). ${ }^{22}$ Under our optimal contract, banks with a large proportion of bad loans are not better off under the scheme than they would be in the absence of a scheme. A voluntary scheme can do no better in terms of ex-ante incentives than our optimal contract (unless it rewards banks with a small proportion of bad loans).

Under mandatory schemes, the non-participation value of equity does not impose any limits, but the fact that the proportion of bad loans is private information does. A full discussion of this issue is beyond the scope of the paper, but we note here that the lemma in that version of the model corresponding to Lemma 2 would still state that a subsidy $s(\theta)$ would have to be non-decreasing (condition (i) of Lemma 2), and that a local optimality condition of the type $\frac{d \Pi(\theta, \theta)}{d \theta}=s(\theta)$ (condition (ii) of Lemma 2) would have to be satisfied for the scheme to be incentive compatible, that is, for banks to truthfully reveal their type. But both conditions taken together imply that the participation profits afforded to banks would have to be non-concave in the proportion of bad loans $\theta$. This constraint limits the extent to which such a scheme punish banks with a large proportion of bad loans, in order to induce ex-ante effort. It might well be binding, depending on the details of how effort choice affects the distribution from which the realization of $\theta$, the proportion of bad loans, is drawn.

\section{Concluding remarks}

It is well known that banks that are essentially insolvent but still operating, i.e. zombie banks, can have incentives to roll over loans of essentially insolvent firms as a form of gambling for resurrection. In general, the more insolvent the bank, the greater the incentives to gamble. This zombie lending can have very bad overall effects for the economy, as was observed in Japan in the 1990s.

At the same time, a regulator is typically at an informational disadvantage vis-a-vis the bank, and cannot tell whether a given bank is part of the "walking wounded" or the "living dead". This means that schemes that aim to induce banks to foreclose potentially produce

\footnotetext{
${ }^{22}$ It is likely that it would only ever be optimal to reward some banks if the social cost of funds $\lambda$ was very low.
} 
information rents. We propose a (voluntary) scheme that can either be interpreted as a form of asset buyback, or as a scheme that subsidizes foreclosure of bad loans. Under the scheme (i) banks reveal their private information, (ii) remove and/or foreclose the bad loans, and (iii) are no better off than they would be in the absence of the scheme, eliminating any information rents.

In the simplest implementation of the scheme, the regulator offers a menu of two-part tariffs, where in each tariff, banks choose a fixed participation fee, and then obtain an associated subsidy per loan that they foreclose. Higher subsidies are associated with higher fees, such that banks with many bad loans choose to pay high fees in exchange for high subsidies, and banks with few bad loans accept low subsidies in order to pay lower fees.

The scheme utilizes the fact that banks have countervailing incentives to minimize information rents: On the one hand, banks have incentives to overstate their proportion of bad loans, to indicate that they are more reluctant to foreclose, and hence that they should pay lower fees. On the other hand, banks have incentives to understate their proportion of bad loans, to indicate that they will benefit less from a given subsidy, and hence that they should pay lower fees. We show that the two features of the model that produce the gambling for resurrection in the first place, i.e. limited liability and uncertainty about future losses on loans that are rolled over, produce incentives to overstate and understate in a way that makes it possible to exactly balance the two incentives. This allows eliminating information rents completely.

We show that if a regulator compares the efficiency gain from having bad loans foreclosed with the cost of inducing banks to foreclose, the optimal contract involves making banks with a relatively low proportion of bad loans foreclose, but letting banks with a relatively high proportion of bad loans gamble. This is because inducing banks with a high proportion of bad loans to foreclose can quickly become very costly.

We also discuss when our scheme is robust to a situation in which banks can foreclose good loans in order to obtain higher transfers from the regulator, how versions of the scheme could be implemented if the regulator knew less than we assumed, how deposit insurance, a social cost of bank failure, and potential bank runs would affect the welfare trade-off, and finally also discuss differences to schemes with mandatory as opposed to voluntary participation, especially in the context of ex-ante moral hazard. 


\section{A Appendix: Proofs}

\section{Proof of Lemma 1:}

We first show that the value of equity is convex in $\gamma$ : We note that the derivative of (3) w.r.t. $\gamma$ is given by

$$
\int_{\bar{\varepsilon}_{0}(\gamma)}^{1}(\rho-\varepsilon) \phi(\varepsilon) d \varepsilon
$$

and that the second derivative is given by

$$
-\left(\rho-\bar{\varepsilon}_{0}(\gamma)\right) \phi(\bar{\varepsilon}) \frac{d \bar{\varepsilon}}{d \gamma}
$$

To evaluate the sign of the second derivative, it is useful to note that

$$
\frac{1}{\theta-\gamma}\left(\rho-\bar{\varepsilon}_{0}(\gamma)\right)=\frac{(1-D)-(1-\rho)}{(\theta-\gamma)^{2}}=-\frac{\partial \bar{\varepsilon}_{0}}{\partial \gamma}
$$

Consider first banks for which $\theta=\frac{1-D}{1-\rho} \equiv \bar{\theta}$. For such banks, $\bar{\varepsilon}_{0}=\rho$, regardless of $\gamma$, and hence the second derivative is always zero. Checking (30), however, we can see that for such banks, the first derivative will always be negative, and hence such banks will foreclose the minimum amount $\gamma=0$, i.e. gamble.

Consider now banks for which $\theta \neq \bar{\theta}$. For such banks, as indicated by (32), $\rho-\bar{\varepsilon}_{0}$ and $\partial \bar{\varepsilon}_{0} / \partial \gamma$ are always of opposite sign, and hence the since $\phi(\varepsilon)>0$, the second derivative is positive, i.e. the value of equity is convex in $\gamma$, such that the optimal choice of $\gamma$ is either 0 or $\theta$.

Furthermore, note that $\pi_{0}^{F}(0)=\pi_{0}^{G}(0)$, that $\pi_{0}^{F}(1)<0$, that $\pi_{0}^{G}(1)=0$, that $\pi_{0}^{F}(\theta)$ is continuous, decreasing, and linear in $\theta$, that $\pi^{G}(\theta)$ is continuous, decreasing, and convex in $\theta$, and that

$$
\left.\frac{\partial \pi_{0}^{G}(x)}{\partial x}\right|_{x=0}=-(1-E[\varepsilon])<-(1-\rho)=\left.\frac{\partial \pi_{0}^{F}(x)}{\partial x}\right|_{x=0}
$$

since $E[\varepsilon]<\rho$. It follows that there exists a unique $\hat{\theta}>0$ such that for $0<\theta<\hat{\theta}$, $\pi_{0}^{G}(\theta)<\pi_{0}^{F}(\theta)$, and for $\hat{\theta}<\theta \leq 1, \pi_{0}^{G}(\theta)>\pi_{0}^{F}(\theta, \theta)$. Since since $\pi_{0}^{F}(\bar{\theta})=0$, we also know that $\hat{\theta}<\bar{\theta}$.

We can therefore see that in general, banks with $\theta<\hat{\theta}$ foreclose, banks with $\theta>\hat{\theta}$ gamble, and banks with $\theta=\hat{\theta}$ are indifferent between foreclosing and gambling.

\section{Proof of Lemma 2:}

The proof for this is standard, see e.g. Fudenberg and Tirole (1991), Section 7.3 for a general discussion. Here, we sketch a simpler proof for completeness. 
Write the incentive compatibility constraint

$$
\Pi\left(\theta^{R}, \theta\right) \leq \Pi(\theta, \theta), \quad \forall \theta^{R}, \theta
$$

as

$$
s\left(\theta^{R}\right) \theta-F\left(\theta^{R}\right) \leq s(\theta) \theta-F(\theta), \quad \forall \theta^{R}, \theta .
$$

This says that telling the truth should maximize the net transfer to the bank.

Locally, incentive compatibility implies the first-order condition

$$
s^{\prime}\left(\theta^{R}\right) \theta-\left.F^{\prime}\left(\theta^{R}\right)\right|_{\theta^{R}=\theta}=0
$$

and the second-order condition

$$
s^{\prime \prime}\left(\theta^{R}\right) \theta-\left.F^{\prime \prime}\left(\theta^{R}\right)\right|_{\theta^{R}=\theta} \leq 0 .
$$

Taking derivatives of (35) w.r.t. $\theta$, inserting the result into (36) and rearranging yields

$$
s^{\prime}(\theta) \geq 0,
$$

i.e. the monotonicity condition is alternative way of stating the local second order condition.

From the first order condition, we also have the differential equation

$$
F^{\prime}(\theta)=s^{\prime}(\theta) \theta
$$

Integrating by parts, we obtain

$$
F(\theta)=\int_{0}^{\theta} s^{\prime}(x) x d x=s(\theta) \theta-\int_{0}^{\theta} s(x) d x,
$$

which implies that

$$
F\left(\theta^{R}\right)-F(\theta)=s\left(\theta^{R}\right) \theta^{R}-s(\theta) \theta+\int_{\theta^{R}}^{\theta} s(x) d x
$$

or, rearranging,

$$
s(\theta) \theta-F(\theta)=s\left(\theta^{R}\right) \theta-F\left(\theta^{R}\right)+\int_{\theta^{R}}^{\theta} s(x) d x-\left(\theta-\theta^{R}\right) s\left(\theta^{R}\right) .
$$

The last two terms taken together are positive since

$$
\int_{\theta^{R}}^{\theta} s(x) d x \geq\left(\theta^{R}-\theta\right) s\left(\theta^{R}\right),
$$


due to the monotonicity condition, i.e.

$$
s(\theta) \theta-F(\theta) \geq s\left(\theta^{R}\right) \theta-F\left(\theta^{R}\right),
$$

i.e. local incentive compatibility plus monotonicity implies global incentive compatibility (modulo some technical integrability conditions).

Lastly, note that the first order condition (35) can also be written in terms of informational rents as

$$
\frac{d U}{d \theta}=s(\theta)-\frac{d \Delta \pi_{0}(\theta)}{d \theta}
$$

So the lemma contains versions of the first and second order conditions for local incentive compatibility, which imply global incentive compatibility in this case.

Proof of Proposition 1: First note that the chosen $s^{*}(\theta)$ is increasing because $\Delta \pi_{0}(\theta)$ is convex, and hence satisfies the first part of Lemma 2. Next note that from (16), it is obvious that the chosen $s^{*}(\theta)$ produces $d U(\theta) / d \theta=0$, and that the given $F(\theta)$ sets $U(\theta)=0, \forall \theta$, which is consistent with $d U(\theta) / d \theta=0$, and hence satisfies the second part of Lemma 2 . We can therefore conclude that the scheme satisfies the incentive compatibility constraint. Furthermore, the zero information rents also satisfy the participation constraint $U(\theta) \geq 0$, and, as argued in the main text, participation implies foreclosure.

Proof of Proposition 2: It is obvious that the proposed optimal contract satisfies (PC). Either from direct consideration of the welfare function, or by an application of the calculus of variations, it is obvious that the proposed contract maximizes welfare, subject to the constraint (PC) (see the main text for a verbal argument). It remains to be shown that the proposed contract satisfies (IC).

As an intermediate result, note that the value of equity under the proposed contract is convex in $\theta^{R}$, as long as reporting $\theta^{R}$ implies receiving the transfer of $\Delta \pi_{0}\left(\theta^{R}\right)$ : Substitute the proposed contract into (7), and take the second derivative w.r.t. $\theta^{R}$ to find that

$$
\frac{d^{2} \Pi\left(\theta, \theta^{R}\right)}{d\left(\theta^{R}\right)^{2}}=-\left(\rho-\bar{\varepsilon}+\frac{d \Delta \pi_{0}\left(\theta^{R}\right)}{d \theta^{R}}\right) \phi(\bar{\varepsilon}) \frac{d \bar{\varepsilon}}{d \theta^{R}}+(1-\Phi(\bar{\varepsilon})) \frac{d^{2} \Delta \pi_{0}\left(\theta^{R}\right)}{d^{2} \theta^{R}},
$$

where $\bar{\varepsilon}$ is given by (8) with the proposed contract substituted in. Some algebra shows that the term $\left(\rho-\bar{\varepsilon}+\frac{d \Delta \pi_{0}\left(\theta^{R}\right)}{d \theta^{R}}\right)$ always has the opposite sign as $d \bar{\varepsilon} / d \theta^{R}$ (this parallels the proof of Lemma 1). The first term is therefore always positive. The second term is always nonnegative since $\Delta \pi_{0}\left(\theta^{R}\right)$ is convex in $\theta^{R}$ for $\theta^{R}>\hat{\theta}$ and flat in $\theta^{R}$ for $\theta^{R} \leq \hat{\theta}$. This implies 
that the second derivative is always positive. ${ }^{23}$

Now note that as a result of this convexity, a bank would always only consider reporting either $\theta^{R}=0$ or $\theta^{R}=\theta$ (as long as it receives the transfer $\Delta \pi_{0}\left(\theta^{R}\right)$ ). We note that (i) $\Pi(\theta, 0)=\pi_{0}^{G}(\theta)$, i.e. that reporting a type of 0 produces the same equity value as when not participating and gambling, and that (ii) $\Pi(\theta, \theta)=\pi_{0}(\theta)$ by the definition of $\Delta \pi_{0}(\theta)$, i.e. that reporting truthfully produces the same equity value as when not participating and taking the privately optimal action (either foreclosing or gambling).

Banks with a type $\theta$ such that $\theta \leq \hat{\theta}$ want to foreclose outside the scheme, i.e. for them, $\pi_{0}(\theta)=\pi_{0}^{F}(\theta) \geq \pi_{0}^{G}(\theta)$. Here, this (trivially) means that $\Pi(\theta, 0)=\pi_{0}^{G}(\theta) \leq \pi_{0}(\theta)=\Pi(\theta, \theta)$.

Banks with a type $\theta$ such that $\theta>\hat{\theta}$ want to gamble outside the scheme, i.e. for them, $\pi_{0}(\theta)=\pi_{0}^{G}(\theta)\left(\geq \pi_{0}^{F}(\theta)\right)$. If their true type $\theta$ is below $\theta^{*}$, they will always receive the transfer, such that $\Pi(\theta, 0)=\pi_{0}^{G}(\theta)=\pi_{0}(\theta)=\Pi(\theta, \theta)$. If their true type $\theta$ is above $\theta^{*}$, they will receive the transfer only when reporting a type $\theta^{R} \leq \theta^{*}$. Let $\Pi_{\Delta \pi_{0}}\left(\theta, \theta^{R}\right)$ denote the (counterfactual) value of equity that they would obtain if they always received the transfer $\Delta \pi_{0}\left(\theta^{R}\right)$ for any $\theta^{R}$ that they reported. This counterfactual value of equity attains the maximum value of $\pi_{0}^{G}(\theta)$ at either $\theta^{R}=0$ or $\theta^{R}=\theta$. The actual value of equity for such banks can be written as

$$
\Pi\left(\theta, \theta^{R}\right)= \begin{cases}\Pi_{\Delta \pi_{0}}\left(\theta, \theta^{R}\right) & \text { for } \theta^{R} \leq \theta^{*} \\ \pi_{0}^{G}(\theta) & \text { for } \theta^{R}>\theta^{*} .\end{cases}
$$

This attains the same maximum value of $\pi_{0}^{G}(\theta)$ at either $\theta^{R}=0$, or at any $\theta^{R} \in\left(\theta^{*}, \theta\right]$.

Taken together, under the proposed contract, it is always the case that $\Pi(\theta, \theta) \geq \Pi\left(\theta, \theta^{R}\right)$, i.e. the proposed contract satisfies (IC).

\section{B Foreclosing good loans}

Would a bank choose to foreclose good loans in addition to, or instead of its bad loans? In general, a bank would foreclose the loans that are "cheaper" to foreclose in terms of their opportunity cost. In particular, a bank will choose to first foreclose bad loans only if

$$
\rho-E[\varepsilon \mid \varepsilon>\bar{\varepsilon}]>\rho_{G}-1,
$$

or

$$
\rho_{G}-\rho<1-E[\varepsilon \mid \varepsilon>\bar{\varepsilon}] .
$$

\footnotetext{
${ }^{23}$ As an alternative to the explicit derivation of the second derivative, note that to obtain the expression equivalent to (3) under the proposed contract, we need to substitute in $\gamma\left(\theta^{R}\right)=\theta^{R}$, and add $T\left(\theta^{R}\right)$ into the integrand. Since (3) is convex in $\gamma$, and $T\left(\theta^{R}\right)$ is (weakly) convex in $\theta^{R}$, the resulting expression is obviously convex in $\theta^{R}$.
} 
As long as $\rho_{G}>\rho$, it is possible that some banks that are very unlikely to survive (and hence have a high $E[\varepsilon \mid \varepsilon>\bar{\varepsilon}]$ ) foreclose good loans before foreclosing bad loans. This happens when the probability of survival is so small ( $\bar{\varepsilon}$ is so high) that the expected return conditional on survival of bad loans that are rolled is very similar to the return on good loans, and the recovery on good loans is much higher than the recovery on bad loans. Since foreclosing good loans makes a bank even less likely to survive (increases $\bar{\varepsilon}$ and hence $E[\varepsilon \mid \varepsilon>\bar{\varepsilon}]$ ), a bank that starts foreclosing good loans would foreclose all good loans before considering foreclosing bad loans. If $\rho_{G} \leq \rho$, all banks will always foreclose all bad loans before considering foreclosing good loans.

We first consider the case where $\rho_{G} \leq \rho$, and then consider the case where $\rho_{G}>\rho$.

Case when $\rho_{G} \leq \rho$ In this case, banks will only consider foreclosing good loans once they have already foreclosed all bad loans. Under our optimal contract, if a bank reports type $\theta^{R}$, where $\theta^{R}>\theta$, it will therefore have to foreclose an amount $\theta^{R}-\theta$ of good loans in addition to foreclosing all of its bad loans. Its value of equity would then be

$$
\Pi\left(\theta, \theta^{R}\right)=\underbrace{1-\theta-\left(\theta^{R}-\theta\right)}_{\text {remaining good loans }}+\underbrace{\left(\theta^{R}-\theta\right) \rho_{G}}_{\text {foreclosed good loans }}+\underbrace{\theta \rho}_{\text {foreclosed bad loans }}-D+\Delta \pi_{0}\left(\theta^{R}\right)
$$

or, rearranging and inserting the expression for $\Delta \pi_{0}\left(\theta^{R}\right)$,

$$
\Pi\left(\theta, \theta^{R}\right)=\pi_{0}\left(\theta^{R}\right)+\left(\rho_{G}-\rho\right)\left(\theta^{R}-\theta\right) \leq \pi_{0}\left(\theta^{R}\right)<\pi_{0}(\theta) .
$$

Since the value of equity from participating and truthfully reporting is equal to $\pi_{0}(\theta)$, a bank would therefore never have incentives to overreport its type, and the optimal contract is robust to this extension.

Case when $\rho_{G}>\rho$ Here, we need to distinguish two subcases. Define the proportion of bad loans $\theta^{\dagger}$ as the proportion for which

$$
1-E[\varepsilon \mid \varepsilon>\bar{\varepsilon}]=\rho_{G}-\rho .
$$

Since $\bar{\varepsilon}$ and hence $E[\varepsilon \mid \varepsilon>\bar{\varepsilon}]$ are increasing in $\theta$, banks with $\theta<\theta^{\dagger}$ are so safe that for them, foreclosing bad loans is less costly than foreclosing good loans. Since foreclosing some bad loans makes them safer, they will foreclose all bad loans before foreclosing any good loans. Conversely, banks with $\theta>\theta^{\dagger}$ will be so risky that for them, foreclosing bad loans will be more costly than foreclosing good loans. Since foreclosing some good loans makes them even riskier, they will foreclose all good loans before foreclosing any bad loans. 
Consider first the safer banks for which $\theta<\theta^{\dagger}$. Using the same argument as in the previous case, we can work out that such banks, when reporting $\theta^{R}$, have a value of equity of

$$
\Pi\left(\theta, \theta^{R}\right)=\pi_{0}\left(\theta^{R}\right)+\left(\rho_{G}-\rho\right)\left(\theta^{R}-\theta\right) .
$$

We note that this expression is convex in $\theta^{R}$, which implies that either, banks will want to report truthfully, or overstate their type type as much as possible. Since the highest type that still obtains a transfer is $\theta^{*}$, we see that such banks will not want to overstate their type at all as long as the recovery $\rho_{G}$ on good loans is not much larger than the recovery on bad loans $\rho$, or

$$
\pi_{0}\left(\theta^{*}\right)+\left(\rho_{G}-\rho\right)\left(\theta^{*}-\theta\right)<\pi_{0}(\theta),
$$

which can be rewritten as

$$
\rho_{G}-\rho<\frac{\pi_{0}(\theta)-\pi_{0}\left(\theta^{*}\right)}{\theta^{*}-\theta}
$$

Consider now the riskier banks for which $\theta>\theta^{\dagger}$. We separately consider the case in which $\theta^{R}<1-\theta$, i.e. banks that foreclose some of their good loans but none of their bad loans, and the case in which $\theta^{R}>1-\theta$, in which banks foreclose all of their good loans and some of their bad loans.

When $\theta^{R}<1-\theta$, banks foreclose an amount $\theta^{R}$ of their good loans, and none of their bad loans. We can write the value of equity as

$\Pi\left(\theta, \theta^{R}\right)=\int_{\bar{\varepsilon}}^{1}(\underbrace{1-\theta-\theta^{R}}_{\text {remaining good loans }}+\underbrace{\theta^{R} \rho_{G}}_{\text {foreclosed good loans }}+\underbrace{\theta \varepsilon}_{\text {remaining bad loans }}-D+\Delta \pi_{0}\left(\theta^{R}\right)) \phi(\varepsilon) d \varepsilon$,

for a suitably defined $\bar{\varepsilon}$.

Rearranging and inserting the expression for $\Delta \pi_{0}\left(\theta^{R}\right)$, we obtain

$$
\Pi\left(\theta, \theta^{R}\right)=\int_{\bar{\varepsilon}}^{1}\left(\theta^{R}\left(\rho_{G}-\rho\right)-\theta(1-\varepsilon)+\pi\left(\theta^{R}\right)\right) \phi(\varepsilon) d \varepsilon
$$

There is now a tradeoff: Foreclosing good loans means a higher recovery of (term in $\rho_{G}-\rho$ ), but also means exchanging the return on good loans against the return on bad loans (term in $1-\varepsilon)$.

Taking derivatives w.r.t. $\theta^{R}$, we can see that

$$
\frac{d \Pi\left(\theta, \theta^{R}\right)}{d \theta^{R}}=\int_{\bar{\varepsilon}}^{1}\left(\left(\rho_{G}-\rho\right)+\frac{d \pi_{0}\left(\theta^{R}\right)}{d \theta^{R}}\right) \phi(\varepsilon) d \varepsilon=(1-\Phi(\bar{\varepsilon}))\left(\left(\rho_{G}-\rho\right)+\frac{d \pi_{0}\left(\theta^{R}\right)}{d \theta^{R}}\right),
$$


which is positive iff $\rho_{G}-\rho>-\frac{d \pi_{0}\left(\theta^{R}\right)}{d \theta^{R}}$. But since

$$
-\frac{d \pi_{0}\left(\theta^{R}\right)}{d \theta^{R}}=\int_{1-(1-D) / \theta^{R}}^{1}(1-\varepsilon) \phi(\varepsilon) d \varepsilon=(1-\Phi(\bar{\varepsilon}))(1-E[\varepsilon \mid \varepsilon>\bar{\varepsilon}]),
$$

we can see that

$$
\rho_{G}-\rho>1-E[\varepsilon \mid \varepsilon>\bar{\varepsilon}]>(1-\Phi(\bar{\varepsilon}))(1-E[\varepsilon \mid \varepsilon>\bar{\varepsilon}]),
$$

i.e. this derivative is always positive. This means that such banks will foreclose as many of their good loans as possible.

When $\theta^{R}>1-\theta$, banks foreclose an amount $1-\theta$ of their good loans (i.e. all of their good loans), and an amount $\theta^{R}-(1-\theta)$ of bad loans. (This means that they roll over an amount $\theta-\left(\theta^{R}-(1-\theta)\right)=1-\theta^{R}$ of bad loans $)$. We can write the value of equity as

$\Pi\left(\theta, \theta^{R}\right)=\int_{\bar{\varepsilon}}^{1}(\underbrace{(1-\theta) \rho_{G}}_{\text {foreclosed good loans }}+\underbrace{\left(\theta^{R}-(1-\theta)\right) \rho}_{\text {foreclosed bad loans }}+\underbrace{\left(1-\theta^{R}\right) \varepsilon}_{\text {remaining bad loans }}-D+\Delta \pi_{0}\left(\theta^{R}\right)) \phi(\varepsilon) d \varepsilon$

Rearranging and inserting the expression for $\Delta \pi_{0}\left(\theta^{R}\right)$, we obtain

$$
\Pi\left(\theta, \theta^{R}\right)=\int_{\bar{\varepsilon}}^{1}\left((1-\theta)\left(\rho_{G}-\rho\right)-\left(1-\theta^{R}\right)(1-\varepsilon)+\pi_{0}\left(\theta^{R}\right)\right) \phi(\varepsilon) d \varepsilon .
$$

Taking derivatives w.r.t. $\theta^{R}$, we can see that

$$
\begin{aligned}
\frac{d \Pi\left(\theta, \theta^{R}\right)}{d \theta^{R}} & =\int_{\bar{\varepsilon}}^{1}\left(1-\varepsilon+\frac{d \pi_{0}\left(\theta^{R}\right)}{d \theta^{R}}\right) \phi(\varepsilon) d \varepsilon \\
& =(1-\Phi(\bar{\varepsilon}))((1-E[\varepsilon \mid \varepsilon>\bar{\varepsilon})-(1-\Phi(\bar{\varepsilon}))(1-E[\varepsilon \mid \varepsilon>\bar{\varepsilon}])) \\
& =(1-\Phi(\bar{\varepsilon})) \Phi(\bar{\varepsilon})(1-E[\varepsilon \mid \varepsilon>\bar{\varepsilon}])>0,
\end{aligned}
$$

i.e. this derivative is always positive. This means that such banks will want to overstate their type as much as is possible.

Since the highest type that still obtains a transfer is $\theta^{R}$, we see that banks with $\theta>\theta^{\dagger}$ will not want to overstate their type as long as

$$
\begin{array}{r}
\int_{\bar{\varepsilon}}^{1}\left(\min \left(\theta^{*}, 1-\theta\right)\left(\rho_{G}-\rho\right)-\min \left(\theta, 1-\theta^{*}\right)(1-\varepsilon)+\pi_{0}\left(\theta^{*}\right)\right) \phi(\varepsilon) d \varepsilon<\pi_{0}(\theta), \\
(1-\Phi(\bar{\varepsilon}))\left(\min \left(\theta^{*}, 1-\theta\right)\left(\rho_{G}-\rho\right)-\min \left(\theta, 1-\theta^{*}\right)(1-E[\varepsilon \mid \varepsilon>\bar{\varepsilon}])+\pi_{0}\left(\theta^{*}\right)\right)<\pi_{0}(\theta),
\end{array}
$$

or

$$
\rho_{G}-\rho<\frac{1}{\min \left(\theta^{*}, 1-\theta\right)}\left(\frac{\pi_{0}(\theta)}{1-\Phi(\bar{\varepsilon})}-\pi_{0}\left(\theta^{*}\right)+\min \left(\theta, 1-\theta^{*}\right)(1-E[\varepsilon \mid \varepsilon>\bar{\varepsilon})),\right.
$$


for suitably defined $\bar{\varepsilon}$. We note that the RHS is always bigger than zero.

We can see that in general, when $\rho_{G} \geq \rho$, as long as the difference $\rho_{G}-\rho$ is small enough, banks will not have incentives to overstate their type. 


\section{References}

Aghion, P., P. Bolton, and S. Fries, 1999, "Optimal Design of Bank Bailouts: The Case of Transition Economies," Journal of Institutional and Theoretical Economics, 155, 51-70.

Ausubel, L. M., and P. Cramton, 2008, "A Troubled Asset Reverse Auction," Working Paper.

Baron, D., and R. Myerson, 1982, "Regulating a Monopolist with Unknown Cost," Econometrica, 50, 911-930.

Caballero, R. J., T. Hoshi, and A. K. Kayshap, 2008, "Zombie Lending and Depressed Restructuring in Japan," American Economic Review, 98, 1943-1977.

Caprio, G. J., and D. Klingebiel, 1996, "A useful new database on episodes of bank insolvency since the late 1970s," World Bank Policy Research Working Paper No. 1620.

Chava, S., and M. R. Roberts, 2008, "How Does Financing Impact Investment? The Role of Debt Covenants," Journal of Finance, 63, 2085-2121.

Corbett, J., and J. Mitchell, 2000, "Banking Crises and Bank Rescues: The Effect of Reputation," Journal of Money, Credit, and Banking, 32, 474-512.

Diamond, D. W., and R. G. Rajan, 2009, "Fear of fire sales and the credit freeze," NBER Working Paper 14925.

Fudenberg, D., and J. Tirole, 1991, Game Theory, MIT Press, Cambridge MA USA.

Goldstein, I., and A. Pauzner, 2005, "Demand-Deposit Contracts and the Probability of Bank Runs," Journal of Finance, 60, 1293-1327.

Gorton, G., and L. Huang, 2004, "Liquidity, Efficiency and Bank Bailouts," American Economic Review, 94, 455-483.

Hoshi, T., and A. K. Kayshap, 2009, "Will the U.S. Bank Recapitalization Succeed? Eight Lessons from Japan," Working Paper.

Klemperer, P., 2010, "The Product-Mix Auction: a New Auction Design for Differentiated Goods," Journal of the European Economic Association, 8, 526-536.

Lewis, T., and D. Sappington, 1989, "Countervailing Incentives in Agency Models," Journal of Economic Theory, 49, 294-313. 
Maggi, G., and A. Rodríguez-Clare, 1995, "On Countervailing Incentives," Journal of Economic Theory, 66, 238-263.

Mitchell, J., 1998, "The Problem of Bad Debts: Cleaning Banks' Balance Sheets in Economies in Transition," CEPR Discussion Paper No. 1977.

Mitchell, J., 2001, "Bad Debts and the Cleaning of Banks' Balance Sheets: An Application to Transition Economies," Journal of Financial Intermediation, 10, 1-27.

Peek, J., and E. S. Rosengren, 2005, "Unnatural Selection: Perverse Incentives and the Misallocation of Credit in Japan," American Economic Review, 95, 1144-1166.

Philippon, T., and P. Schnabl, 2009, "Efficient Recapitalization," NYU Working Paper No. FIN-09-014.

Philippon, T., and V. Skreta, 2010, "Optimal Interventions in Markets with Adverse Selection," Working Paper. 


\section{CEMFI WORKING PAPERS}

0801 David Martinez-Miera and Rafael Repullo: "Does competition reduce the risk of bank failure?".

0802 Joan Llull: "The impact of immigration on productivity".

0803 Cristina López-Mayán: "Microeconometric analysis of residential water demand".

0804 Javier Mencía and Enrique Sentana: "Distributional tests in multivariate dynamic models with Normal and Student $t$ innovations".

0805 Javier Mencía and Enrique Sentana: "Multivariate location-scale mixtures of normals and mean-variance-skewness portfolio allocation".

0806 Dante Amengual and Enrique Sentana: "A comparison of mean-variance efficiency tests".

0807 Enrique Sentana: "The econometrics of mean-variance efficiency tests: A survey".

0808 Anne Layne-Farrar, Gerard Llobet and A. Jorge Padilla: "Are joint negotiations in standard setting "reasonably necessary"?".

0809 Rafael Repullo and Javier Suarez: "The procyclical effects of Basel II".

0810 Ildefonso Mendez: "Promoting permanent employment: Lessons from Spain".

0811 Ildefonso Mendez: "Intergenerational time transfers and internal migration: Accounting for low spatial mobility in Southern Europe".

0812 Francisco Maeso and Ildefonso Mendez: "The role of partnership status and expectations on the emancipation behaviour of Spanish graduates".

0813 Rubén Hernández-Murillo, Gerard Llobet and Roberto Fuentes: "Strategic online-banking adoption".

0901 Max Bruche and Javier Suarez: "The macroeconomics of money market freezes".

0902 Max Bruche: "Bankruptcy codes, liquidation timing, and debt valuation".

0903 Rafael Repullo, Jesús Saurina and Carlos Trucharte: "Mitigating the procyclicality of Basel II".

0904 Manuel Arellano and Stéphane Bonhomme: "Identifying distributional characteristics in random coefficients panel data models".

0905 Manuel Arellano, Lars Peter Hansen and Enrique Sentana: "Underidentification?".

0906 Stéphane Bonhomme and Ulrich Sauder: "Accounting for unobservables in comparing selective and comprehensive schooling".

0907 Roberto Serrano: "On Watson's non-forcing contracts and renegotiation".

0908 Roberto Serrano and Rajiv Vohra: "Multiplicity of mixed equilibria in mechanisms: a unified approach to exact and approximate implementation".

0909 Roland Pongou and Roberto Serrano: "A dynamic theory of fidelity networks with an application to the spread of HIV / AIDS".

0910 Josep Pijoan-Mas and Virginia Sánchez-Marcos: "Spain is different: Falling trends of inequality".

0911 Yusuke Kamishiro and Roberto Serrano: "Equilibrium blocking in large quasilinear economies".

0912 Gabriele Fiorentini and Enrique Sentana: "Dynamic specification tests for static factor models". 
0913 Javier Mencía and Enrique Sentana: "Valuation of VIX derivatives".

1001 Gerard Llobet and Javier Suarez: "Entrepreneurial innovation, patent protection and industry dynamics".

1002 Anne Layne-Farrar, Gerard Llobet and A. Jorge Padilla: "An economic take on patent licensing: Understanding the implications of the "first sale patent exhaustion" doctrine.

1003 Max Bruche and Gerard Llobet: "Walking wounded or living dead? Making banks foreclose bad loans". 